\title{
Experimentos portáteis para aula sobre indução eletromagnética, geradores e motores
}

Portables experiments to learning on electromagnetic induction, generators and motors

\author{
G. G. de Oliveira ${ }^{1}$, A. H. Vasconcelos ${ }^{1}$, L. C. N. Sousa ${ }^{1}$, J. S. da $\operatorname{Costa}^{1}$, A. P. Lima ${ }^{1}$, \\ A. Silva ${ }^{2}$ e C. Chesman ${ }^{* 2,3}$ \\ ${ }^{1}$ Universidade Federal do Rio Grande do Norte, Escola de Ciências e Tecnologia, Natal, RN, Brasil. \\ ${ }^{2}$ Fractal Experimentos, 59078-400, Natal, RN, Brasil. \\ ${ }^{3}$ Universidade Federal do Rio Grande do Norte, Departamento de Física, 59078-790, Natal, RN, Brasil.
}

Recebido em 04 de novembro de 2021. Aceito em 09 de novembro de 2021.

\begin{abstract}
Neste trabalho, apresentaremos experimentos portáteis no intuito de abordar os conceitos da indução eletromagnética com alunos do Ensino Básico. Os materiais utilizados para a realização dos experimentos são de fácil aquisição e o conjunto deles pode ser adquirido na forma de um kit, facilmente transportável. A proposta é que os alunos aprendam os conceitos por meio de discussão em sala e da execução de experimentos. Para isso, será dado maior destaque às aulas interativas em detrimento das expositivas. Assim, nos inspiramos na metodologia desenvolvida pelo grupo da Universidade de Rutgers, liderado pela professora Eugenia Etkina. A fundamentação dessa proposta é que os alunos estudem e aprendam os conceitos físicos de forma semelhante à forma que os cientistas trabalham para construir o conhecimento científico. Tal metodologia foi denominada "Investigative Science Learning Environment" (ISLE). Desta feita, os alunos são apresentados ao método científico, ainda no Ensino Médio, de forma concreta, em que a observação, a proposição e a refutação de hipóteses são fundamentais para a criação de um modelo para o fenômeno físico estudado. Para avaliar a metodologia e os experimentos portáteis, apresentamos uma proposta de sequência didática a ser aplicada em uma turma da terceira série do Ensino Médio.
\end{abstract}

Palavras-chave: Experimento Portátil, Metodologia ISLE, Motores elétricos.

In this paper we will present a portables experiments in order to approach the concepts of electromagnetic induction to Basic Education students. The materials used to perform the experiments are easy to acquire, and the set of them can be purchased in the form of an experimental kit, easily transportable. The proposal is that students learn the concepts through classroom discussion and the execution of experiments, with greater emphasis on interactive classes over lectures. For this, we were inspired by the methodology developed by the group from Rutgers University, led by Professor Eugenia Etkina. The foundation of this proposal is that student's study and learn physical concepts similar to the way scientists work to setup scientific knowledge. Such methodology was called "Investigative Science Learning Environment" (ISLE). In this method, students are introduced to the scientific method, in high school, in a concrete way where observation, proposition and refutation of hypotheses are fundamental for creating a model for the physical phenomenon studied. To evaluate the methodology and use of the portable experiment, we present a proposal for a didactic sequence to be applied to a twelve-year high school class.

Keywords: Portable Experiment, ISLE Methodology, Electric Motors.

\section{Introdução}

Historicamente, no Brasil, o ensino de Física é feito de maneira tradicional, por meio de aulas expositivas, apoiadas unicamente no livro didático e com pouca presença de aulas experimentais que possam auxiliar na compreensão dos conceitos físicos envolvidos ou mesmo tornar o aluno parte integrante do processo de ensino e aprendizagem [1]. A grande dificuldade de mudar o paradigma de um ensino tradicional para um ensino mais

\footnotetext{
* Endereço de correspondência: chesman@fisica.ufrn.br
}

participativo se deve ao fato de termos no país uma baixa formação docente em metodologias alternativas de ensino [2, 3]. Podemos citar, ainda, como fator adicional, a inexistência de laboratórios de ensino de Física em boa parte das escolas públicas, como apontam estudos [4].

Nas últimas décadas, foram instituídas políticas públicas visando a melhoria na qualidade do ensino e a adoção de metodologias mais participativas que pudessem alterar a prática pedagógica vigente, tais como a Lei de Diretrizes e Bases da Educação NacionalLDBEN [5] e os Parâmetros Curriculares Nacionais para o Ensino Médio-PCNEM [5]. Podemos, ainda, enfatizar a iniciativa da Sociedade Brasileira de Física (SBF) com a 
criação do Programa Nacional de Mestrado Profissional em Ensino de Física (MNPEF).

O MNPEF é um programa de ampla abrangência, contendo atualmente 63 polos espalhados por todo o território nacional que vêm contribuindo para a melhoria da formação docente. Casanova, S.S \& Zara, R. A. 6 apontam em seu estudo que uma média de $47 \%$ dos trabalhos defendidos no programa, no período 2015 2018, são de cunho experimental, sendo estes a maioria dos trabalhos defendidos pelo Programa. Sabendo que os alunos do MNPEF são docentes em atividade na rede básica de Ensino, a partir desse resultado, podemos inferir que existe uma carência que gera uma demanda da Rede Básica pela criação e produção de experimentos de baixo custo, o que pode refletir na falta de laboratórios adequados nessas escolas. Podemos ressaltar, ainda, que há um consenso entre os professores da rede básica sobre a importância da atividade experimental no processo de ensino e aprendizagem de seus alunos.

No intuito de resolver esse paradigma, as escolas particulares passaram a contemplar, em seus currículos, aulas de laboratórios de Física, sendo estes muitas vezes dotados de vários equipamentos que abrangem conteúdos ministrados desde o Ensino Fundamental anos finais, até a terceira série do Ensino Médio. Todavia, as escolas públicas não conseguiram acompanhar o ritmo das escolas particulares, não dispondo, em sua maioria, de laboratórios de Física. Para além da falta de laboratório, não é difícil encontrarmos escolas públicas que, mesmo dispondo de laboratórios, não possuem um corpo docente ou técnico capacitado a utilizar os equipamentos que, nessas situações, acabam sendo subutilizados.

Em 2020, com a pandemia da COVID-19, houve uma brusca mudança de realidade no mundo que impactou diretamente as atividades de ensino. As aulas em todo o país foram inicialmente canceladas e, posteriormente, cada estado teve que decidir sobre suas respectivas políticas educacionais mediante uma crise sanitária mundial. Professores tiveram que se adaptar rapidamente à nova realidade do ensino remoto e ao ensino híbrido (em que parte das aulas é on-line e parte é presencial) em algumas situações. Superada a dificuldade inicial de aprendizado das ferramentas de teletrabalho por parte dos professores, um ano depois, ainda temos um problema: a impossibilidade de realizar, de forma contínua, atividades de cunho experimental.

A falta de acesso ao ambiente do laboratório de Física e ao formato de aulas remotas privilegia aulas expositivas em detrimento de aulas experimentais, tornando ainda mais difícil a adoção de metodologias mais participativas e alternativas à metodologia tradicional de ensino.

Nesse sentido, este trabalho tem por objetivo apresentar uma proposta de uso de um minilaboratório, um conjunto de materiais acessíveis e um kit, que permite a execução de diferentes experimentos de física, que propiciará o estudo dos conceitos de indução eletromagnética.
A ideia é que tais conceitos possam ser aprendidos pelos alunos a partir da execução de experimentos sobre o assunto e consequente discussão em sala. Nessa proposta, é dada maior ênfase às aulas interativas, inspiradas na metodologia ISLE "Investigative Science Learning Environment".

\section{Materiais Usados nos Experimentos Portáteis Proposto}

Para a realização dos experimentos portáteis (usaremos a abreviação ExP ou ExPs), todos os materiais são apresentados em um caixote de madeira tipo MDF, Figura 1] que foi cortado a laser, medindo $21,0 \mathrm{~cm}$ de comprimento, $17,0 \mathrm{~cm}$ de largura e 7,0 cm de altura, Estas dimensões foram escolhidas para que todos os experimentos sejam portáteis e que a caixa possa acomodar facilmente os materiais a seguir:

a. 01 Multímetro digital, ponteira com garras tipo jacaré

b. 01 Bobina de fio esmaltado

c. 01 Carcaça da bobina com ímã

d. 01 Ímã cúbico de neodímio

e. 01 Ímã cilíndrico de neodímio

f. 01 Ímã em formato de anel

g. 01 Cabo duplo, bananas/terminais

h. 01 Minigerador

i. 01 Manivela

j. 01 Lâmpada Led/Bocal, cabo duplo/banana

k. 01 Base do motor

1. 01 Suporte para pilhas

m. 02 pilhas AA

n. 01 Bobina com 6-8 voltas

Vale ressaltar que todos esses materiais são de fácil aquisição no comércio local da maioria das cidades do Brasil ou em sítios de vendas de produtos na internet. Por exemplo, qualquer multímetro que meça voltagem

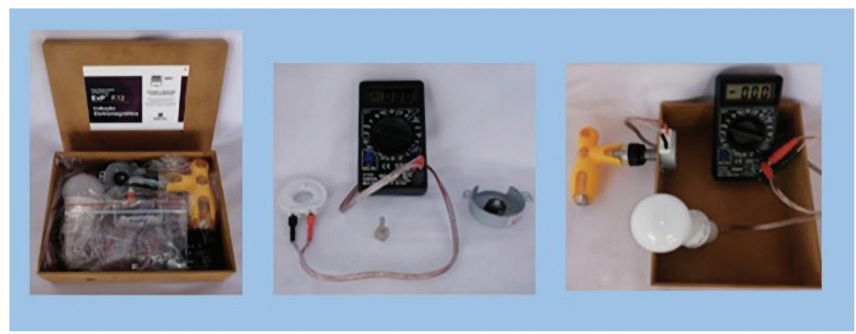

Figura 1: Fotografia com todos os materiais do experimento dentro e fora do caixote. À esquerda, todos os materiais dentro do pequeno caixote portátil. No centro, a bobina ligada ao multímetro digital com ímãs de neodímio e a carcaça do minigerador. À direita, a manivela amarela acoplada ao minigerador que acende uma lâmpada residencial e um multímetro para medição da voltagem gerada.

Fonte: Imagem dos autores. 
na faixa de milivolts pode ser usado. Os ímãs de neodímio podem ser adquiridos diretamente no sítio da empresa Mercado Livre. A peça central deste kit é o minigerador, que é simplesmente um motor que gira o prato de forno de micro-ondas (muito popular nas cozinhas atuais) com a observação de que na compra deve-se solicitar que o motor tenha o eixo de fixação de metal, por ser mais robusto.

\section{ISLE - Ambiente de Aprendizagem Científica Experimental}

Dentre vários métodos de ensino existentes, nesse estudo, nós optamos em utilizar o ISLE (Ambiente de Aprendizagem Cientifica Experimental). Este método de aprendizagem foi criado pelo grupo da "Graduate School of Education, Rutgers University" dos Estados Unidos da América, liderados pela professora Eugenia Etkina [7, 8]. Há, inclusive, um sítio na internet com vasta informação sobre este método: https://www.isle physics.net/. Passamos a descrever o método em uma tradução livre das informações deste sítio com pequenas adaptações à realidade brasileira.

O ISLE é um jogo epistêmico e cognitivo que emula o método pelo qual os físicos criam seu conhecimento. Neste contexto de ser um jogo, a chave para não o deixar desinteressante é seguir como uma investigação misteriosa, na qual os alunos constroem seus conceitos de física e desenvolvem habilidades de aprendizagem da ciência, simulando os processos que os físicos usam para construir conhecimento. As etapas do ciclo do ISLE são as seguintes:

1. Os alunos encontram algum fenômeno físico interessante que precisa ser explicado. Normalmente, uma atividade experimental.

2. Os alunos reúnem dados sobre o fenômeno, identificam padrões interessantes e apresentam várias explicações para o porquê de o fenômeno estar acontecendo. Inicialmente, todas as ideias são aceitáveis, para incentivar o cognitivo a pensar sobre o problema em questão.

3. Eles, então, testam suas explicações/previsões, conduzindo um ou mais experimentos de teste. O objetivo principal é eliminar as explicações em vez de "prová-las". Essa é a chave para a natureza não desinteressante do processo. No ISLE, "prever" significa dizer qual seria o resultado do experimento de teste se uma determinada hipótese fosse verdadeira.

4. As ideias que não são eliminadas são mantidas e testadas novamente com mais experimentação.

5. Finalmente, os alunos aplicam as ideias que estabeleceram para resolver problemas do mundo real, por exemplo, com uma aplicação tecnológica.

Para entender os três componentes deste método, seguiremos o diagrama de bloco (às vezes, chamado

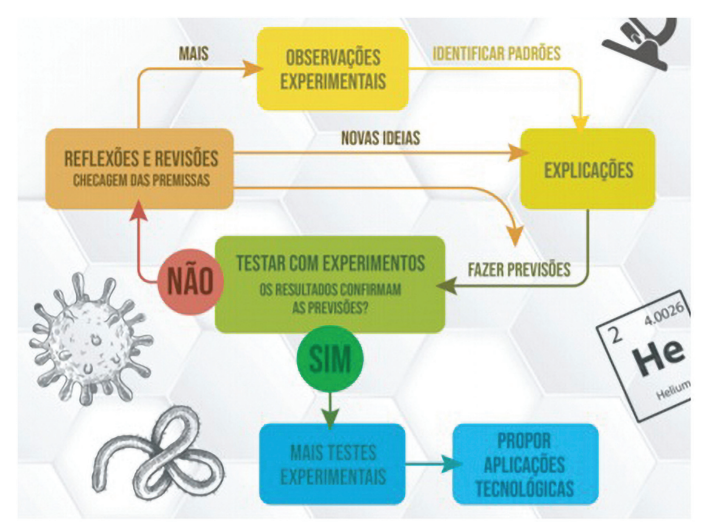

Figura 2: Ciclo ou diagrama de bloco do ISLE. O início é uma observação ou uma experimentação, seguindo-se a construção de conceitos de física e desenvolvendo habilidades de aprendizagem da ciência, simulando os processos que os físicos usam para construir conhecimento. Por fim, chega-se às aplicações tecnológicas.

Fonte: Imagem dos autores.

mapa conceitual) esquemático do método ISLE, também chamado de ciclo ISLE, que é apresentado na Figura 2

O primeiro componente é um ciclo de raciocínio lógico que se repete a cada novo tópico aprendido. A lógica de raciocínio é uma junção de raciocínio indutivo e hipotético-dedutivo:

Indutivo: Os experimentos observacionais fornecem dados aos alunos e padrões interessantes que precisam ser explicados, criando os conhecimentos básicos sobre o tema em estudo. Nitidamente, na vida cotidiana, não temos conhecimento de inúmeros fenômenos naturais. Assim, um dos objetivos de uma realização experimental é contribuir para aquisição de conhecimento prévio para a aprendizagem científica do tema. Com estes conhecimentos, o estudante poderá pensar em como agir para entender e resolver o problema. Os alunos podem gerar várias explicações com base em conhecimento prévio e raciocínio analógico.

Hipotético-dedutivo: Se esta explicação estiver correta (realizar um experimento de teste), então isso e aquilo devem acontecer (previsão baseada na explicação). Mas, se não aconteceu, minha ideia não é correta (julgamento). Ou aconteceu, portanto, minha ideia ainda não foi refutada (julgamento).

O segundo componente do ISLE é um conjunto de ferramentas representacionais que os alunos aprendem a usar para passear pelo ciclo do ISLE e entender e resolver problemas do mundo real (aplicativos). Estes incluem: imagens, gráficos, diagramas de movimento, diagramas de força, gráficos de barra de impulso-momento, gráficos de barra de energia e trabalho, diagramas de circuito elétrico, diagramas de raios, diagramas de frente de onda etc.

O terceiro componente do ISLE é o desenvolvimento de um conjunto de habilidades científicas ou hábitos 
mentais científicos que permitem aos alunos passear pelo ciclo do ISLE e resolver problemas do mundo real (aplicações), pensando como um cientista físico. Os alunos são capazes de identificar as suposições que estão fazendo e como essas suposições afetam o resultado. Observe que essa habilidade se aplica a vários contextos. As suposições são feitas ao projetar um experimento de teste e podem afetar o resultado desse experimento ou as conclusões tiradas desse experimento. O conjunto completo de habilidades científicas e os múltiplos contextos em que ocorrem são codificados nas rubricas de habilidades científicas.

O jogo ISLE serve para que os alunos aprendam física, compreendendo como devem jogar este jogo epistêmico. Os estudantes de física têm plena consciência de que precisam "jogar um jogo" quando estão aprendendo física. A questão é que tipo de jogo queremos que eles joguem? A coisa mais essencial sobre o ISLE é que ele apresenta aos alunos um conjunto de regras para um jogo não ameaçador que os ajuda a construir suas identidades e habilidades como cientistas praticantes.

\section{A Sequência Didática para os ExPs de Indução Eletromagnética, Motores e Geradores}

A sequência didática se divide em três (03) etapas de realizações experimentais alinhadas com aprendizagens sobre a lei da indução eletromagnética e suas principais aplicações tecnológicas, os motores e os geradores.

Cabe ressaltar aqui que a expressão "sequência didática" tornou-se conhecida no Brasil, em especial, a partir dos trabalhos de M. A. Moreira [9] e nitidamente a metodologia ISLE e as UEPS, fundamentadas na Teoria de Aprendizagem Significativa 9, dialogam entre si, pois ambas são apoiadas no método científico centrado na observação prática e/ou experimental de um dado fenômeno. Inclusive, os três momentos aqui descritos da sequência didática são semelhantes aos três componentes da ISLE ou, ainda mais, ambas metodologias possuem componente do ciclo de raciocínio lógico que se repete a cada novo tópico aprendido.

No primeiro momento pedagógico, o professor apresenta aos estudantes os materiais que compõem os $\mathrm{ExP}^{\prime}$ s e o seu uso. Explica o que é uma espira, composta pelo fio esmaltado enrolado na forma de bobina, como se usa o multímetro (antes de chegar neste tema, muito possivelmente, nas atividades práticas sobre eletricidade e magnetismo, já foi apresentado com se usa este instrumento de medidas elétricas), o que é um ímã de neodímio, enfim, um momento de contextualização experimental com a apresentação e uso de todos os itens que compõem este ExP. Com esses diálogos, o passo inicial da problematização inicial foi executado.

Chegamos, então, ao segundo momento pedagógico, no qual o professor apresenta qualitativamente os experimnetos, isto é, não se fazem aqui medidas, apenas

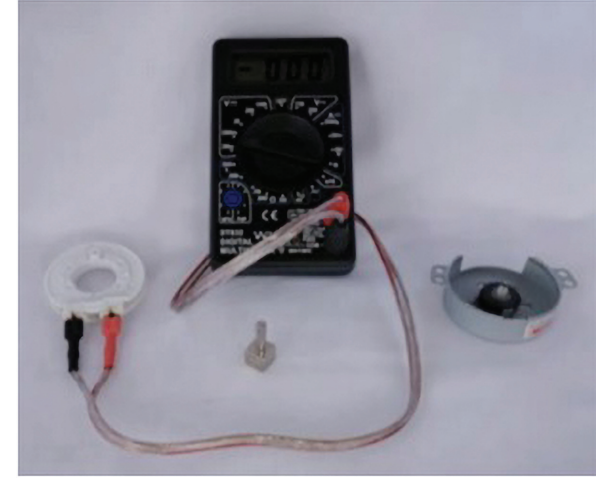

Figura 3: Fotografia dos imãs (cubo e cilíndrico) ao centro e abaixo do multímetro, bobina (a esquerda na cor branca). Cabos ligam a bobina ao multímetro (na escala de 200 milivolts VDC) usados para observar o fenômeno da indução eletromagnética ao se aproximar os ímãs da bobina. Visualiza-se, por fim, a detecção com a variação dos dígitos do multímetro.

Fonte: Imagem dos autores.

observações qualitativas. Em seguida, fazem-se as conexões elétricas entre a bobina e o multímetro, entre o minigerador, a lâmpada e o multímetro e, também, a ligação do minimotor com a bateria e o ímã de neodímio. Após cada conexão, individualmente, seguem os momentos de observação. Para a bobina, o ímã de neodímio e o multímetro, pergunta-se o que deve ocorrer ao se aproximar a bobina do ímã, que valor deve-se medir no multímetro (voltagem, corrente ou resistência elétrica)?

A Figura 3 apresenta os materiais usados para essas primeiras observações experimentais. Aguardam-se as respostas, fazem-se anotações e a primeira aproximação do ímã com a espira é efetuada. Em seguida, comentase o observado, anotam-se os valores e novas perguntas podem ser efetuadas, sempre com a resposta advinda da observação da experimentação. Podem surgir mais perguntas do tipo: a voltagem registrada depende de que parâmetros, proximidade do ímã com a espira, da velocidade do aproximação do ímã, do ângulo entre a bobina e do ímã etc? É momento de aguçar a observação experimental com as perguntas e a direta observação por parte dos estudantes ou, ainda, podem-se escutar perguntas por parte deles e, novamente, lembrá-los de que a resposta deve vir da observação prática.

Na parte seguinte, no segundo ciclo ISLE, fazem-se as medidas quantitativas, medem-se os valores de voltagem gerados em cada situação prática das observações qualitativas e quanto foi o valor gerado em unidades de milivolt.

Das observações, solicitamos que seja feita uma classificação ou caracterização dos padrões das experimentações. Perguntamos quais parâmetros físicos (campo magnético, campo elétrico, temperatura, pressão, corrente e voltagem elétrica, etc) são importantes para se chegar a uma lei que explica todos estas observações. Há alguma equação representativa 
para explicar o que é observado? Ainda no segundo momento pedagógico, inicia-se a construção da equação que relacione as grandezas físicas que foram analisadas. Discute-se o método de trabalho do descobridor deste fenômeno (Michael Faraday), que não possuía muitos conhecimentos matemáticos para propor uma equação representativa das observações. Explicamos, ainda, que foram necessários alguns anos de comunicações entre os cientistas até que James Maxwell apresentasse sua formulação matemática da lei da indução que, em notação moderna, adaptada ao ensino de Física em disciplinas introdutórias, pode ser expressa assim na equação (1)

$$
\varepsilon_{\text {induzida }}=-\frac{\Delta \Phi_{\text {fluxo magnético }}}{\Delta t_{\text {tempo }}} ;
$$

que representa a força eletromotriz induzida (medida no voltímetro, com o circuito aberto, sem carga) que é proporcional ao negativo da variação do fluxo magnético dividido pela variação temporal. Explica-se que, no sistema internacional de medidas, a voltagem elétrica é medida em volts, o fluxo magnético em medidas de campo magnético, $\mathrm{Tm}^{2}$ (tesla vezes metros quadrado) e o tempo em segundos. Na hipótese desta equação ser válida, se pergunta sobre o sinal ser negativo, que é algo substancialmente importante comentar. Este sinal representa que a variação do fluxo temporal induzirá uma força eletromotriz negativa a essa variação. Este fato pode ser observado diretamente na medida da voltagem medida no voltímetro (observando-se a mudança do sinal), todas as vezes que se inverte o sentido ímã ou a bobina ao se aproximar ou se afastar. Tal fato indica o que chamamos de lei de Lenz, isto é, a evidência da lei da conservação da energia neste sistema eletromagnético e cinético. Assim, se deve introduzir a lei de Lenz, da observação experimental em conjunto com a hipótese de a Equação 1 estar correta. Assim, a Lei de Lenz mostra que há uma reação contrária à ação provocada pelo ímã ou pela bobina, de forma que, se o sul do ímã se aproxima da bobina, o sentido da força eletromotriz é horário.

Com a lei básica da indução eletromagnética devidamente explorada, pode-se passar para o terceiro momento pedagógico, que é aplicação deste conhecimento. A pergunta chave poderia ser: quais equipamentos, encontrados nas residências, poderiam ser associados à lei da indução eletromagnética? Em que parte(s) destes aparelhos a indução eletromagnética se manifesta? Você poderia descrever, de forma simplificada, como ela se manifesta? Ouvem-se as respostas, que inicialmente são as máquinas residenciais, liquidificador, batedeira, máquina de lavar, furadeira, enfim, máquinas motrizes. Nitidamente, tais respostas surgirão porque os estudantes já conhecem estes equipamentos do cotidiano e talvez haja a resposta de construir um gerador. Neste momento, é importante ressaltar aos estudantes que para estas máquinas funcionarem é preciso antecipadamente que ocorra a geração da energia elétrica.

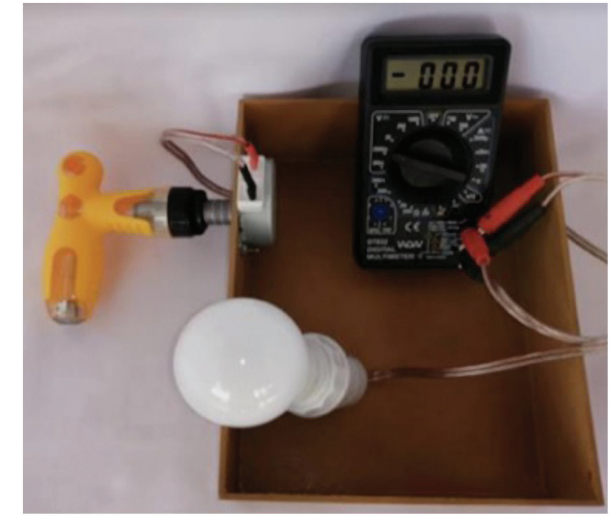

Figura 4: Fotografia com os materiais para demonstrar a geração de energia elétrica, manivela amarela, minigerador (fixado no caixote), cabos (ligam o mini-gerador a lâmpada e ao multímetro), multímetro e lâmpada residencial tipo LED. Fonte: Imagem dos autores.

Logo, é necessário inicialmente, entender a tecnologia de funcionamento de um gerador elétrico.

Depois, apresenta-se o uso do minigerador, que faz uso de um movimento cíclico, com o giro da manivela girando um ímã interno que está dentro da bobina e, assim, produz-se energia elétrica a partir da energia do movimento. Faz-se a demonstração com o acendimento de uma lâmpada residencial, tipo LED, mostra-se que este pequeno gerador é capaz de acender a lâmpada facilmente (Figura 4 ) e os materiais para esta realização prática. Pode-se perguntar qual o valor da voltagem gerada por este minigerador. Ouvem-se as respostas e suas explicações e, em seguida, mede-se a voltagem o multímetro, com e sem a lâmpada no circuito, podendo comentar sobre a diferença dos conceitos de "força eletromotriz" e "voltagem elétrica", o que fica nítido com as medidas no multímetro, com e sem a lâmpada no circuito, isto é, com e sem a carga elétrica ligada. Discutese sobre o sistema de engrenagem que fez aumentar a velocidade do ímã interno à bobina. Para finalizar esta seção de investigação do minigerador e para usar um dos sentidos do corpo humano como sensor de grandeza elétrica, pode-se perguntar se este minigerador é capaz de provocar um choque elétrico forte em uma pessoa. Para responder experimentalmente, sugerimos que os dois terminais de saída do gerador sejam conectados somente entre os dedos da mão direita do estudante curioso, pois o choque é razoavelmente forte e não se deve passar corrente elétrica no corpo na região próxima ao coração humano. Faz-se o giro e observa-se a reação do aluno atiçador.

$\mathrm{Na}$ continuidade do terceiro momento pedagógico, o assunto agora são as máquinas motrizes eletromagnéticas, os chamados motores elétricos, que são os instrumentos que foram fundamentais para a chamada Segunda Revolução Industrial. Em praticamente todas as indústrias, foram introduzidos os motores para execução de diversas tarefas, substituindo o trabalho 
braçal e as máquinas a vapor. O início é mais uma vez com uma pergunta: o que ou quais componentes são necessários para se construir um motor elétrico? Há inúmeras formas de se montar um motor elétrico e, neste momento, pode-se solicitar que façam uma consulta via internet sobre os diferentes tipos de motores e, diante dos resultados apresentados, pode-se discutir quais são os componentes essenciais para haver um motor elétrico, isto é, transformar energia elétrica em energia mecânica, energia cinética de movimento. Depois de ouvir e analisar em conjunto com os estudantes todas as ideias e suposições, apresenta-se um protótipo de um motor de corrente contínua com escovas. Mostrase o motor em funcionamento e deixa-os observar e experimentar, fazer mudanças do tipo: inverter a bobina, mudar o tipo de ímã, mudar as posições relativas do ímã e da bobina etc. Pode-se instigar os estudantes a projetar outros tipos de motores. No link abaixo, há um roteiro de uma aula experimental com estes materiais:

https://fractal.ind.br/pdfs/ExP_F12_Inducao_Eletrom agnetica.pdf

\section{Conclusões e Perspectivas}

Apresentamos uma nova ferramenta de aprendizagem, nomeada de ExP (Experimento Portátil), que facilita a operação de experimentação pelo professor e aluno, tornando o estudante protagonista, pois permite que o próprio aluno controle toda a sua experimentação. Não há necessidade de infraestrutura laboratorial para a realização da prática, inclusive, pode ser realizada na própria sala de aula ou nos lares dos aprendizes.

No artigo, apresentamos em detalhes a idealização e a implementação de um ExP sobre a Lei da Indução Eletromagnética, Geradores e Motores e suas sequências didáticas. Este trabalho foi iniciado nas atividades laboratoriais de ensino de física e a criação e montagem dos primeiros protótipos foi realizado com financiamento público, junto ao CNPq. Posteriormente, o desenvolvimento desses protótipos foi feito pela microempresa Fractal Experimentos, que hoje atua desenvolvendo, fabricando e vendendo esses experimentos portáteis. Esta é uma forma positiva da avaliação de que os Experimentos Portáteis são uma alternativa assertiva de aprendizagem significativa.

Ressaltamos que ainda se farão necessárias mais avaliações, principalmente, de métodos avaliativos na área da educação-pedagogia, para aferir com mais precisão sobre os limites desta ferramenta de aprendizagem. Por fim, estes primeiros resultados apresentados aqui são parte integrante da dissertação de mestrado de um dos autores desse artigo, no MNPEF Polo 51-UFRN.

\section{Referências}

[1] I.J. Pozo e M.A.G. Crespo, A Aprendizagem e o Ensino de Ciências - Do conhecimento cotidiano ao conhecimento científico (Editora ARTMED, Porto Alegre, 2006).
[2] L.H.M. Arthury e E.A. Terrazan, Rev. Bras. Ensino Fís. 40, e3403 (2018).

[3] R.C. Diogo e S.T. Gobara, em: XVII Simpósio Nacional de Ensino de Física: Programa e Resumos (Sociedade Brasileira de Física, São Luis, 2007), p. 165.

[4] C.M. Pedrisa, Ciência \& Ensino 11, 9 (2001).

[5] MINISTÉRIO DA EDUCAÇÃO, Parâmetros Curriculares Nacionais para o Ensino Médio (PCNEM), disponível em: http://portal.mec.gov.br/index.php?option=com_c ontent\&view $=$ article\&id=12598:publicacoes\&catid=195: seb-educacao-basica.

[6] S.S. Casanova e R.A. Zara, Arquivos do Mudi 24, 267 (2020).

[7] E. Etkina, American Journal of Physics, 83669 (2015).

[8] E. Etkina e A. Van Heuvelen, em: Research-Based Reform of University Physics, editado por E.F. Redish e P. Cooney (American Association of Physics Teachers, College Park, 2007), v. 1.

[9] M.A. Moreira, Teorias de Aprendizagem (Editora Pedagógica e Universitária, São Paulo, 2011), $2^{\text {a }}$ ed. 